\title{
Use of conventional tomography to evaluate changes in the nasal cavity with rapid palatal expansion
}

Jacqueline R. Palaisa

West Virginia University

Follow this and additional works at: https://researchrepository.wvu.edu/etd

\section{Recommended Citation}

Palaisa, Jacqueline R., "Use of conventional tomography to evaluate changes in the nasal cavity with rapid palatal expansion" (2005). Graduate Theses, Dissertations, and Problem Reports. 2191.

https://researchrepository.wvu.edu/etd/2191

This Thesis is protected by copyright and/or related rights. It has been brought to you by the The Research Repository @ WVU with permission from the rights-holder(s). You are free to use this Thesis in any way that is permitted by the copyright and related rights legislation that applies to your use. For other uses you must obtain permission from the rights-holder(s) directly, unless additional rights are indicated by a Creative Commons license in the record and/ or on the work itself. This Thesis has been accepted for inclusion in WVU Graduate Theses, Dissertations, and Problem Reports collection by an authorized administrator of The Research Repository @ WVU. For more information, please contact researchrepository@mail.wvu.edu. 


\title{
USE OF CONVENTIONAL TOMOGRAPHY TO EVALUATE CHANGES IN THE NASAL CAVITY WITH RAPID PALATAL EXPANSION
}

\author{
Jacqueline R. Palaisa, D.M.D. \\ Thesis Submitted to the School of Dentistry \\ of West Virginia University \\ In Partial Fulfillment of the Requirements for \\ The Degree of
Master of Science
In
Orthodontics \\ Peter Ngan, D.M.D., Chair \\ Chris Martin, D.D.S., M.S. \\ Thomas Razmus, D.D.S., M.S. \\ Department of Orthodontics \\ Morgantown, West Virginia \\ 2005
}




\title{
ABSTRACT
}

\section{Use of Conventional Tomography to evaluate changes in the Nasal Cavity with Rapid Palatal Expansion}

\author{
Jacqueline R. Palaisa, D.M.D. \\ The relationship between nasal airway resistance and rapid palatal expansion remains \\ controversial. The purpose of this study is to determine the anatomical changes within \\ the nasal cavity following expansion using conventional tomography. Nineteen patients \\ (ages 8-15) were included in the study. Tomograms were taken before expansion, \\ immediately after expansion, and three months later. Areas for the left and right anterior, \\ middle and posterior nasal cavity and total volume were calculated using computer \\ software (AutoCAD LT 2005). Data was analyzed using paired t-tests. Significant \\ increases in area were found in the anterior, middle and posterior nasal cavity at all time \\ periods. Significant increases in volume were also found. No significant differences were \\ found in the area or volume of the left and right sides of the nasal cavity. These data \\ suggest that an increase in area and volume of the nasal cavity occurs with RPE and \\ remains three months after expansion.
}




\section{DEDICATION}

To my husband Steve, you are my best friend and I appreciate the support you have given me over the past three years. Without your encouragement, I may have never pursued this degree. Thank you and I look forward to spending the rest of my life with you. I love you.

To my son Trevor, you have brought me more happiness than I thought was possible. You were only a year and a half old when I started this program and now you are a young man of four and a half. The time has flown by. I know you have no idea of the sacrifice these past three years have been, but I assure you that they would have been much worse without your beautiful smile and constant love and affection. I love you.

To my mother Diane, you have proven that a woman can have a career and be a great mother at the same time. You set a wonderful example for me over the years. Thank you for teaching me the importance of a good work ethic and having good values to live by. Thank you for your support over the years. I love you.

To my father Jim, thank you for you support and encouragement over the years. Thank you for teaching me the importance of investing in my retirement and in having a strong work ethic. I love you.

To my sisters Andrea and Carrie, thank you for being wonderful sisters. I've have always enjoyed our friendship. I am proud of both of you and honored to be your sister. Thanks for your love and support and know that I love both of you.

To my aunt Susan and my grandparents, Jim and Jean, thank you for your love and support over the years. I will never forget the wonderful times we have spent together and the help you have given me with Trevor. I love you. 


\section{ACKNOWLEDGEMENTS}

To the following individuals, I express my sincere thanks and appreciation:

Dr. Peter Ngan, my committee chairman, for accepting me into the program and allowing me to fulfill my dream of becoming and orthodontist. Thank you for your guidance and encouragement over the past three years.

Dr. Chris Martin, thank you for your assistance on this project and in the clinic. You have made the past three years much more enjoyable and I will miss you.

Dr. Thomas Razmus, thank you for your guidance on this project. You were never too busy if I have a question and you were always available. Thank you.

Dr. Erdogan Gunel, thank you for help in statistically analyzing the data and interpretation of the results.

Dr. Joe Mullins and Dr. Thomas Shipley, thanks for your support and friendship throughout the past three years. I have enjoyed getting to know you and your families and I will miss you both very much. I have learned so much from you both personally and professionally. You are great classmates and I wish you all the success in the world and happiness in the future. We will always be "the chosen ones".

To my fellow residents (past and present) Brian, Nihar, Mike, Bret, Matt, Russ, Meredith, Todd, Mike, Jennifer, Spencer and Glenn, thanks for all the memories. It has been a lot of fun and I will miss you all. I've made a lot of wonderful friendships and I will never forget you.

To Pam, Charlotte, Jackie, Joyce and Tammy, thank you for your support and friendship over the past three years. You made coming to school everyday enjoyable. 


\section{TABLE OF CONTENTS}

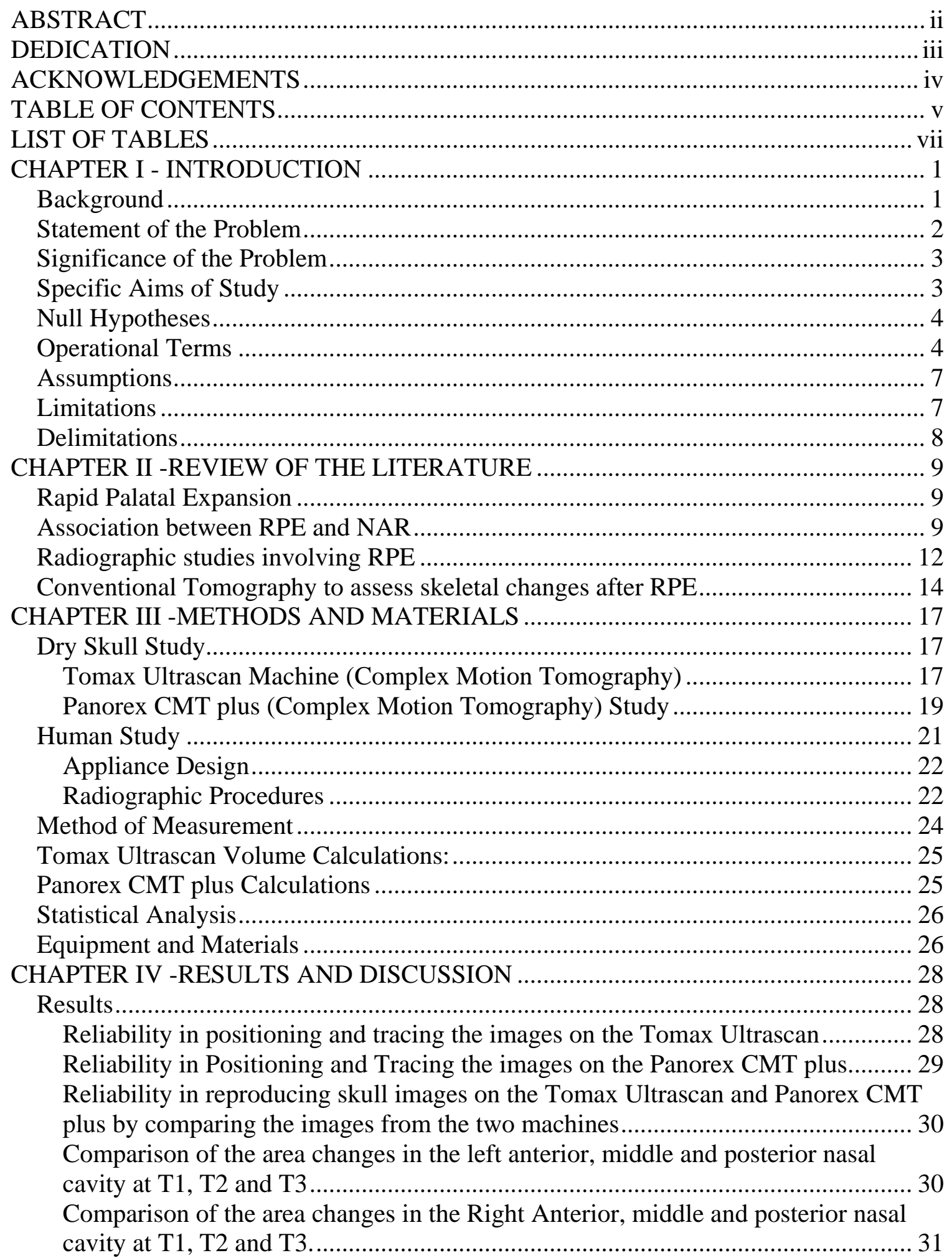


Comparison of total area changes (left and right) of the anterior, middle and posterior nasal cavities at T1, T2 and T3 ......................................................... 32

Comparison of changes in the area of the Left versus the Right nasal cavities........ 33

Total volume changes of the nasal cavity from T1, T2 and T3 ............................. 35

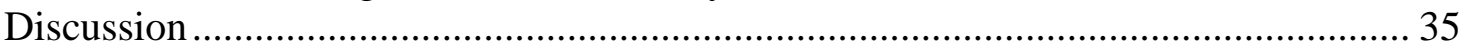

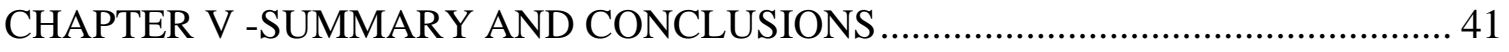

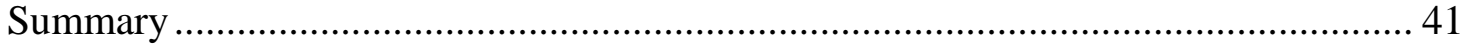

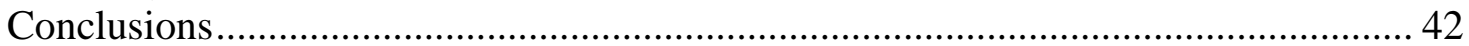

Comparison of Left Anterior, Middle, and Posterior Nasal cavity at T1, T2 and T3.

Comparison of Right Anterior, Middle, and Posterior Nasal Cavity at T1, T2, and T3

Comparison of total area changes (left and right) of the anterior, middle, and posterior nasal cavities at time T1, T2, and T3................................................ 43

Comparison of changes in the area of the left versus the right nasal cavity ............. 43

Total volume changes of the nasal cavity from T1, T2, and T3 ........................... 44

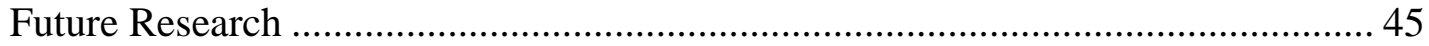

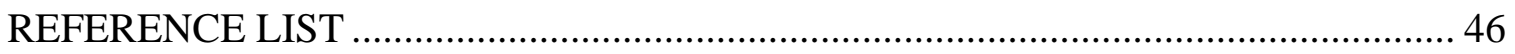

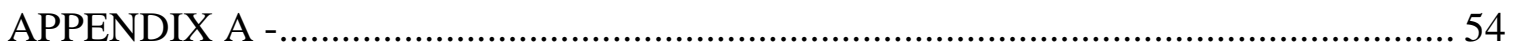

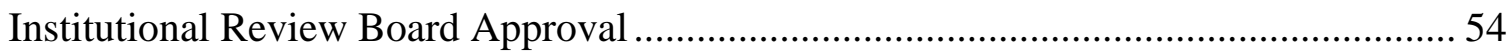

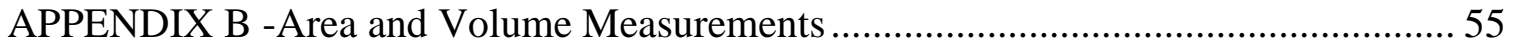

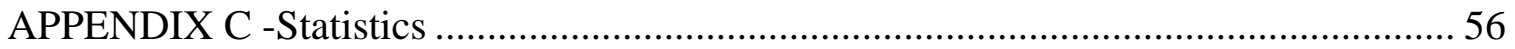

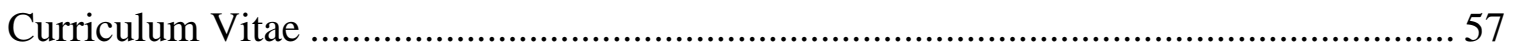




\section{LIST OF TABLES}

Table 1: Mean changes in left anterior, middle and posterior nasal cavities from T1, T2 and $\mathrm{T} 3, \mathrm{p}<0.05$.

Table 2: Mean changes in the right anterior, middle, and posterior nasal cavities from T1, $\mathrm{T} 2$ and $\mathrm{T} 3, \mathrm{p}<0.05$...

Table 3: Mean area changes of the right and left (total area changes) anterior, middle,

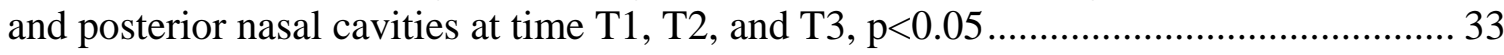
Table 4: Comparison of changes in the mean areas of the left versus right nasal cavities

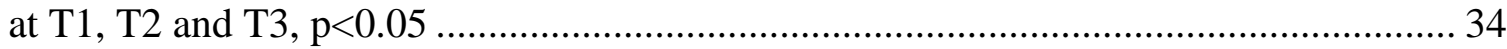
Table 5: Mean Area changes in the right and the left nasal cavities at times T1, T2, and

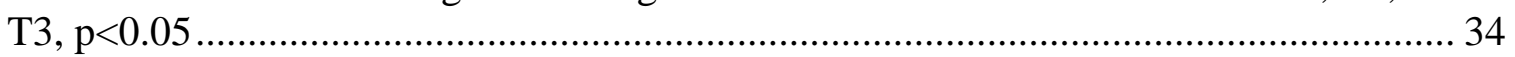
Table 6: Total Volume Changes in the Nasal Cavity from T1, T2 and T3. 


\section{CHAPTER I - INTRODUCTION}

\section{Background}

Rapid palatal expansion (RPE) is a commonly used orthodontic procedure for correcting maxillary transverse deficiency. It is often used in young patients presenting with a unilateral or bilateral posterior crossbite in association with a skeletal constriction of the palate. In recent years, RPE has been suggested in the treatment of medical problems such as nasal airway insufficiency (mouth- breathers), septal deformity, nasal infection, allergic rhinitis, and obstructive sleep apnea.(1-7) Rationalization of the clinical use of RPE for its rhinological effects remains controversial. Several studies have concluded that it can be beneficial in mouth-breathers and in patients with obstructive sleep apnea if they also initially presented with a constricted palate.(8;9)

The suggestion of possible rhinologic effects of RPE dates back as early as 1860 . The first written account of a patient treated with RPE was published by E. C. Angell.(10) According to Pfaff, Lohman, and Derechsweiler, the first rhinologist to be interested in the separation of the maxilla was Eysell of Berlin in 1886. $(1 ; 11 ; 12)$ Eysell suggested that expansion for a collapsed maxilla would influence the inner conformation of the nose, thus increasing the nasal volume. His idea was not accepted by his peers and this discouraged his future endeavors. Studies in this area gained popularity in the early 1900’s. Radiography, especially with the use of frontal cephalometric radiographs, was

utilized to study the anatomical changes within the nasal cavity following RPE. (3;13-15) 
However, some inherent problems exist when conclusions are derived from frontal cephalometric radiographs alone. These radiographs restrict the evaluation of the nasal air passage to only the transverse and vertical planes. Cross-sectional images of the nasal cavity cannot be assessed to provide information about the sagittal dimension. Comparisons of subsequent films for longitudinal studies are difficult due to superimposition of other bony structures. Another problem with frontal cephalometric radiographs is that it assumes expansion is uniform throughout the entire length (anteroposteriorly) of the nasal cavity. (16)

Conventional tomography provides information that can be used to determine the area and volume of the nasal cavity in three dimensions.(17;18) In contrast to frontal P-A radiographs, tomographic images can be made along the length of the nasal airway. This allows for comparison of the anterior nasal cavity to the middle and posterior nasal cavities.

The purpose of this study is to determine if there are changes in area and volume in the nasal cavity following RPE therapy.

\section{Statement of the Problem}

Does the area and volume of the nasal cavity change uniformly throughout the entire length of the nasal cavity with RPE therapy? Can these changes be determined using conventional tomography? 


\section{Significance of the Problem}

It has been suggested that RPE therapy can be helpful in treating patients with nasal resistance problems, including obligatory mouth-breathers. However, rationalization of the clinical use of RPE for its rhinological effects remains controversial. Information on the effects of RPE on the area and volume of the nasal cavity would help clinicians to determine if RPE can be useful in treating medical problems such as allergic rhinitis, obstructive sleep apnea and nasal airway insufficiency.

\section{Specific Aims of Study}

A. To determine the area and volume changes within the nasal cavity before treatment (T1), immediately following active expansion with RPE (T2), and three months following active expansion (T3).

B. To determine the area and volume changes along the length of the nasal passage, namely the anterior nasal cavity, middle nasal cavity, and posterior nasal cavity following RPE treatment.

C. To determine if the changes in area and volume in response to RPE therapy are symmetrical between the right and left nasal cavity. 


\section{Null Hypotheses}

A. There are no significant changes in the area and volume of the nasal cavity immediately following active expansion and three months following active expansion.

B. There are no significant differences in the area and volume of the anterior nasal cavity, middle nasal cavity and posterior nasal cavity following rapid palatal expansion treatment.

C. There are no significant differences in the area and volume of the right and left sides of the nasal cavity following rapid palatal expansion.

\section{Operational Terms}

1. Conventional Tomography - a technique of radiography by which a radiograph is produced while shifting the film and x-ray source in opposite directions around an axis located near the region of interest. Thus, movement blurs structures outside the zone of sharpness, while maintaining sharpness in the region of interest.

2. Rapid Palatal Expansion (RPE) - orthopedic widening of the two halves of the maxilla or palatal shelves, usually using high load systems. Also, called Rapid Maxillary Expansion or RME in the literature. 
3. Frontal cephalometric radiograph- a radiograph taken with the x-ray source located behind the head and the x-ray film located in front of the face and taken according to cephalometric conventions. Also called a postero-anterior (PA) cephalometric radiograph.

4. Lateral cephalometric radiograph - a radiograph taken according to cephalometric conventions, with the x-ray source facing the right side of the face and directed perpendicular to the midsagittal plane. The x-ray film is adjacent to the left side of the face typically in the United States and adjacent to the right side in Europe. This radiograph is used to measure and determine craniofacial relationships.

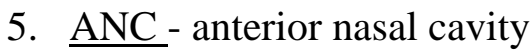

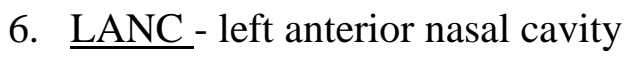

7. RANC - right anterior nasal cavity

8. $\quad$ MNC - middle nasal cavity

9. $\quad$ LMNC - left middle nasal cavity

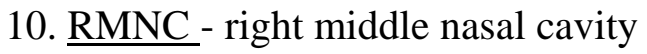

11. PNC - posterior nasal cavity

12. LPNC - left posterior nasal cavity

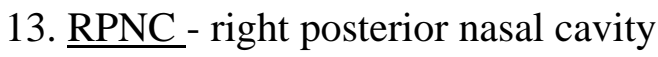

14. $\underline{\mathrm{T} 1}$ - pretreatment tomograms

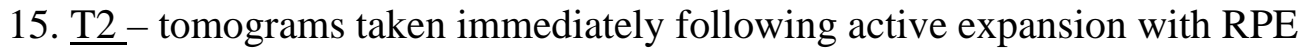

16. $\underline{\mathrm{T} 3}$ - tomograms taken three months after active expansion with RPE

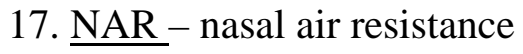




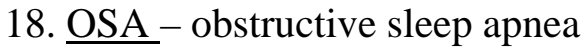




\section{Assumptions}

1. Rapid palatal expansion improves nasal airway resistance.

2. Sutural separation of the maxilla is accomplished in all patients treated with RPE therapy.

3. Conventional tomography can be used to obtain information to determine the area and volume of the nasal cavity in three dimensions: transverse, vertical and sagittal.

4. There is no difference in the type of expansion produced by different types of expanders.

\section{Limitations}

1. All patients receiving at least $4 \mathrm{~mm}$ of skeletal expansion using a banded or bonded Hyrax RPE as part of their orthodontic treatment plan during the fall of 2003 were asked to participate.

2. Treatment of patients will be provided by different individuals and may not be uniform (e.g. Number of turns of jackscrew or the amount of sutural separation may differ).

3. Growth is assumed to be linear within the three month period included in the study and will not be considered.

4. Patients are treated using different types of RPE. 


\section{Delimitations}

1. Patients with a history of craniofacial anomalies (cleft palate/ lip, hormonal or growth irregulaties) are excluded from the study.

2. Pre-treatment tomograms of the subjects will serve as their own reference point for comparisons immediately following active expansion and three months later.

3. One researcher will perform all of the radiographic procedures.

4. The expansion will involve a minimum of $4 \mathrm{~mm}$ of expansion (16 turns)

5. Types of expansion appliances were limited to banded appliances with Hyrax screws and hygienic bonded expanders with Hyrax screws. 


\section{CHAPTER II -REVIEW OF THE LITERATURE}

\section{Rapid Palatal Expansion}

Rapid Palatal Expansion (RPE) has been an established treatment for maxillary constriction in orthodontics for many years. It is used in predominantly young patients presenting with a unilateral or bilateral posterior crossbite in association with a skeletal constriction of the maxilla. There are numerous appliances and variations in appliance designs that are used for rapid palatal expansion. Studies by Asanza (19) and Reed (20) compared bonded verses banded types of rapid palatal expanders and found that there was no significant difference between the different types of expanders. Also, superiority of one type of expansion technique over another could not be determined.

\section{Association between RPE and NAR}

Starting in the early 1900's, an interest in the possible beneficial rhinological side effects after palatal expansion developed. G.V.I. Brown (1903) advocated the use of RPE for obtaining greater nasal width. (2) He claimed that RPE could correct a deviated septum and relieve conditions associated with nasal and pharyngeal mucous membrane hypertrophy. Since then, this interest has grown and there have been many nasal air resistance (NAR) studies completed on patients who have received RPE therapy. 
The purpose of many of the NAR and RPE studies was to see if there was a medical justification to expand the palate. The vast majority of studies found beneficial side effects on NAR after RPE, but one study by Wertz had inconclusive results that could not be used to justify palatal expansion for the improvement of nasal air resistance and a variety of other rhinological ailments.

Wertz studied changes in airflow after RPE.(7) He found that all of the patients in his study had an increase in air volume during maximum ventilation but the amount varied. He concluded that the location and degree of obstruction accounted for this variation. He also stated that palatal expansion for the sole purpose of respiratory insufficiency was unjustified unless the obstruction was in the lower anterior part of the nasal passages. Bicakci found that the changes in airflow after RME were stable over time. (21)

Several other studies reported positive medical results after RPE but had disclaimers such as the changes were greatest in patients with the most initial obstruction (22). Another study stated that there were positive changes in NAR after RPE, but the patients with the greatest changes were the ones who presented with the greatest NAR in the beginning. (23)

Many of the NAR and RPE studies reported benefits after RPE that included a decreased NAR, decreased incidence of mouth breathing and obstructive sleep apnea. In 1975, Gray presented results from patient questionnaires of 310 patients treated with RPE. (24) Gray reported that $87 \%$ of treated patients changed from mouth to nose breathers and $60 \%$ reported fewer upper respiratory infections. Thirty percent even commented on improvement in their general well-being and concentration. In 1987, 
Gray studied whether treatment with RME addressed the problems associated with an impaired nasal airway.(25) Gray looked at mouth-breathing, snoring, speech nasality, exercise tolerance and recurrence of bacterial sinusitis. The results showed an $82 \%$ change to nasal breathing, decreased snoring, improved speech, improved exercise tolerance and a decrease frequency of bacterial sinusitis. Overall, Gray reported considerable improvements in the nasal airway after RME.

After the overwhelming positive results on the nasal air resistance after RPE, the medical community began to investigate using palatal expansion as a therapy for such medical conditions as allergies, snoring, and obstructive sleep apnea. In the late 1990’s, Palmisano (26) and Cistulli (27) observed that many patients with obstructive sleep apnea (OSA) typically presented with maxillary constriction and resultant mouth-breathing. Cistulli also performed RME on 10 of these patients (6 surgically assisted and 4 RME) and found that there were improvements in snoring and hypersomnolence in 9 out of 10 of them.

Several studies found that the changes in NAR associated with RPE were stable over time. Hershey, Stewart and Warren (1976) found that there was a 45\% reduction in NAR and that this was stable for three months after. (28) Turbyfill (1976) followed the same patients and found that there was an additional 8\% decrease in NAR in the treated group when compared to the control group. (29) Hartgerink (1986) evaluated changes in NAR with RPE and found that there was a significant decrease in the mean NAR in approximately $70 \%$ of the patients after one year. (30) White also evaluated NAR after RPE in 1989 and observed post-treatment stability, but noted individual variation. He found that the patients with the greatest initial NAR value had the most NAR reduction. 
(31). Timms (1984) reviewed medical records of patients treated with RME and found that there is a relationship between increased facial height, narrow maxillae, impaired nasal airway, mouth-breathing and respiratory disease.(32) He felt that the use of RME for the relief of "anterior nasal stenosis" was efficacious. In a continuation of this earlier study, Timms (1987) found a connection between reduced nasal function and respiratory disease. He found that the advantages of RME are general widening of the airway (decreased NAR) and no scarring since the treatment is non-surgical. (33)

\section{Radiographic studies involving RPE}

Many studies involving cephalometrics have been used to assess the stability of the increased nasal width after RPE. Wright(14), Derichsweiler (15), Haas(3), and Basciftci(34-36) all reported increases in the nasal cavity width after RPE. Krebs(13) reported an initial increase in nasal cavity width that narrowed two months into retention. Cephalometrics has also been used in studies by Haas (3;37), Krebs(38), Timms(39), Wertz(40), and Bell(41) to show that the sutural separation of the maxilla is non-uniform. Studies using frontal cephalometric radiographs suggested that RPE results in separation of the maxillary suture superoinferiorly in a triangular pattern, with the base located at the oral side and the apex toward the nasal area.(38;40;41) Cameron (2002) investigated long-term effects induced by RME followed by comprehensive orthodontic treatment in 42 patients using cephalometrics. (42) He found that the changes were still stable at a mean age of 20. Cross (2000) compared the transverse dimensions of skeletal, dental, and nasal structures of a group of patients with maxillary "narrowness" before and after 
RME with an untreated control group using PA cephalometric radiographs. (43) Cross found that there were small, but statistically significant changes in the maxillary width, and that there is variability in the pattern of expansion depending on the patient's age and maturity level. Memikoglu (1999) performed a prospective study of the changes in the transverse plane following the use of an acrylic bonded RME in 14 growing individuals.(44) He found that the changes after RME were stable at the end of fixed appliance therapy. Asanza (1997) found that the changes after expansion are not symmetrical and the expansion varied from left to right and varied in different individuals. (19)

Studies involving occlusal films show that the mid-palatal suture opening is nonparallel and wedge-shaped. The greatest opening is in the anterior and it narrows progressively toward the posterior. (3;31;34) A study by Thorn (45) used occlusal radiographs to report an increase of $1.7 \mathrm{~mm}$ in nasal width in 40 patients after treatment with RPE. (range of 0.4-5.7mm). He also noted that this gain was usually lost in retention after two months. In another study, Wertz postulated that a narrowing of the nasal cavity caused by an obstruction in the anterior-inferior part of the nose could possibly be relieved by opening of the maxillary suture. He also felt that a constriction in a more posterior or superior area of the nasal cavity would have little chance of benefiting from RPE therapy. (7)

Montgomery et al (1979)(46;47) used computed tomography to study the sagittal dimensional changes along the nasal air passages. This study demonstrated that CT data can be used to determine the volume along the nasal airway. In another study, Vig(16) used CT on a patient after RPE. He found that there was a persistently increased post- 
expansion in the anterior region, but little to no change in the posterior aspect of the nose. He cautioned against using PA cephalometrics to assess changes in the nasal airway since they can only demonstrate two planes.

There are pros and cons to each method of radiographic evaluation. Computed tomography can provide image data useful to determine the volume along the nasal airway (46;47), but it is expensive and exposes the patient to more radiation than any of the other radiographic modalities. Computed tomography also may require a hospital setting and a medical radiologist. PA cephalograms can be used to view the nasal cavity, but they can only view changes in two planes with no consideration for differential changes occurring throughout the length of the nasal cavity.

Clark et al (1990) studied the radiation dose delivered to several tissues within the head during simulated dental implant radiographic procedures using conventional tomography and CT-Scan techniques(48) The results were compared to those reported for panoramic and intra-oral radiography. CT scanning delivered the most radiation while the absorbed doses from panoramic and intra-oral radiographs were similar to that of conventional tomography. Conventional tomography is an alternative approach to computed tomography and can provide similar diagnostic information. (49)

\section{Conventional Tomography to assess skeletal changes after RPE}

Conventional tomography is a radiographic technique designed to provide relatively sharp images of the principal objects located in the plane of interest (focal 
plane). (50) This is accomplished by blurring the images of structures that reside on either side of the plane.

Basic tomographic equipment consists of an $\mathrm{x}$-ray tube, radiographic film, and a rigid connecting rod capable of rotating about a fixed fulcrum. (51) The x-ray tube and film are located on opposite sides of the fulcrum, which situates within the focal plane. The fulcrum is the only point in the system that remains fixed during the exposure of the film. The tube and film move simultaneously in opposite directions around the fulcrum. Objects located in the focal plane will have a sharper image. Images of objects located outside the focal plane will be blurred due to motion unsharpness. (51)

Blurring, the distortion of objects outside the focal plane, can be affected by the type of tomographic movements used. Tomographic movement is the motion through which the tube and film travel. Movements may be linear, circular, elliptical, figure eight, hypocycloidal, or trispiral. (51)

Maximum blurring of structures outside the focal plane is achieved when objects are perpendicular to the $\mathrm{x}$-ray source. Linear tomography provides the least optimal blurring, since objects lying outside the focal plane are positioned parallel with the motion of the tube. (52) A more complex or multidirectional motion will result in sharper tomographic images. Hypocycloidal tomography is one type of multidirectional motion that results in maximum blurring of structures both close to, and distant from the focal plane. (51) Less distortion of tomographic images is expected from the hypocycloidal motion pattern since the $\mathrm{x}$ rays transverse the object in the focal plane at continuously changing angles. (50-53) 
The width of the focal plane is called the tomographic layer. $(51 ; 52)$ Selection of the thickness of "slice" is determined by the tomographic angle. Two types of tomographic angles are described: the wide and narrow angle. (53)

Wide-angle tomography results in a thin tomographic layer. Wide-angle tomography is useful in studying tissues that result in images with high contrast such as bone. It permits better visualization of finer or smaller structures that would normally be obscured by superimposition. $(51 ; 52)$ Narrow-angle tomography or zonography uses an angle less than 10 degrees. The tomographic layer is thicker and this method is useful to visualize soft tissues characterized by low contrast. (useful with tissues with low contrast i.e. lung)(51;52)

There is no published research that uses conventional tomography to determine the anatomical changes within the nasal cavity in the transverse, vertical and sagittal dimensions following non-surgically assisted RPE. However, Schwarz (2002) published an article where he examined nine patients for nasal septal deviation after surgicalorthodontic rapid maxillary expansion. (54) He used four coronal tomograms that were taken prior to and not less than 4 months after surgical intervention (total of eight tomograms). Significant increases in the available nasal airway space were recorded, but it was attributed primarily to shrinkage of inflamed nasal mucosa. 


\section{CHAPTER III -METHODS AND MATERIALS}

This section is based on a pilot study performed by Dr. Ahn Tran and is divided into two parts. The first part involves the use of a dry cadaver skull. The reliability of using the Tomax Ultrascan Cephalostat (Incubation Industries, Inc., Ivyland, PA) and the Panorex CMT plus (Imaging Sciences International, Inc) for cross-sectional images along the nasal airway was determined with the skull on each machine. The dry skull was also used to set the parameters of these tomographic machines prior to their use on human subjects in the second part of this study.

\section{Dry Skull Study}

\section{Tomax Ultrascan Machine (Complex Motion Tomography)}

A file was created for the skull prior to its imaging with the Tomax Ultrascan. A name and identification number were assigned to the skull and stored on the computer's hard drive. From the computer menu, "tomography” was selected. Next, the frame size was entered, "small” for the skull. From this information, the Tomax Ultrascan automatically sets the exposure ranges for the particular radiographic procedure. Operator's errors were minimized due to predetermined values for x-ray exposure, type of tomographic motion, and slice thickness set at default protocol. The default protocol setting for the dry skull is 50 kilovoltage $(\mathrm{kVp})$, a hypocycloidal trajectory motion, and one millimeter slice thickness. A filtration device was added for radiography of the dry skull to compensate for the lack of soft tissue. A motorized platform allowed for 
automatic control of skull position. "Homing" of the Tomax Ultrascan prior to radiographic exposure was completed once all information for the skull was entered into the computer. Homing allows the unit's platform, $x$-ray tube and film cassette to be returned to a standardized "zero point" home base position. This step was important because it permitted the Tomax Ultrascan to be repositioned to a specific radiographic procedure location from a consistent "home” position. Once the Tomax Ultrascan platform was in position, the skull was mounted into the head holder.

Consistency of the skull placement was determined by the use of a chin cup device, left and right ear rods, and millimeter calibrations located on the Tomax Ultrascan. Horizontal and vertical positioning was recorded during each mounting prior to exposure with the $\mathrm{x}$-ray beam. The width of the Tomax Ultrascan with the skull in position was recorded. These calibrated reference points were recorded to ensure repositioning accuracy of the skull during each subsequent tomogram taken of the nasal cavity. Finally, a scribe line was drawn in pencil on the skull distal to the maxillary right canine to show the site of the first tomographic slice. A 5 inch by 12 inch film cassette was loaded into the holder and locked into place.

Once the skull was securely in place, the first set of three cross-sectional tomograms was taken along the nasal airway. A vertical scribe line was drawn on the vertical portion of the Tomax Ultrascan and was used to locate the first of the three crosssectional images. The platform was moved to visually line up the scribe line distal to the maxillary right cuspid of the skull to the line on the machine. The distance from porion to the scribe line was measured. This number was entered into the machine as the $\mathrm{X}$ coordinate for the position of the tomographic slice. The Y coordinate was zero. The 
first cross-sectional tomogram at the region of the cuspid represented the anterior nasal cavity, ANC, and provided the reference point where the second and third cross-sectional images were made. The Tomax Ultrascan was instructed to make the second crosssectional tomogram $10 \mathrm{~mm}$ distal to ANC (Y coordinate was 0 ). This image was located near the maxillary second premolar and it represented the middle nasal cavity, MNC. The third cross-sectional tomogram was made $20 \mathrm{~mm}$ distal to ANC (Y coordinate was zero again), approximately distal to the maxillary first molar. This last image represented the posterior nasal cavity, PNC. The skull was removed from the Tomax Ultrascan and stored properly after each set of tomograms.

This procedure was repeated twice at one week intervals in order to obtain a second and third set of tomograms. This was done to determine positioning error of the skull and reliability of the Tomax Ultrascan and the operator in reproducing the tomograms consistently. The length of time for this procedure was less at the subsequent sets of tomograms since the computer's database saved most of the operational procedure information.

These tomograms of the nasal cavity were traced on matte acetate tracing paper with a $0.5 \mathrm{~mm}$ pencil. The tomograms were retraced with an ultra fine point permanent marker to improve visualization for scanning.

\section{Panorex CMT plus (Complex Motion Tomography) Study}

While collecting patient data, a new tomography machine was purchased and the Tomax Ultrascan was replaced. The dry skull study was repeated on the new machine in 
order to compare the images from the two machines and determine if the patient could be repositioned in a repeatable manner on the new machine.

The Panorex CMT plus has several differences from the Tomax. It has a 44\% magnification, whereas the Tomax Ultrascan has 22\% magnification. Thus, a 0.875 magnification factor was used to correct the final areas for images taken on the Panorex CMT plus. The magnification factor was verified by comparing a specific linear measurement on the MNC of T1, T2 and T3 on both machines. The calculated magnification factor was 0.863 versus 0.875 . This translated into a difference of $0.3 \mathrm{~mm}$ and was determined to be non-significant.

The horizontal and vertical rulers that were used to verify patient position were no longer present. The Tomax Ultrascan had a platform that the patient stood upon and the platform moved the patient to image the slices of the nasal cavity. On the Panorex CMT plus, the patient stands on the ground and the machine moves around the patient to record the different slices of the nasal cavity. Operator errors were minimized by using the default protocol settings for $\mathrm{x}$-ray exposure $(50 \mathrm{kVp})$ and type of motion (hypocycloidal), but the default setting for slice thickness was $6 \mathrm{~mm}$. The slice thickness was reduced to $2 \mathrm{~mm}$. This is the thinnest slice thickness setting possible for the machine. “Homing” of the Panorex CMT plus machine is done automatically before you enter information for a new patient or existing patient.

In order to compare the two machines, the dry skull study was repeated on the Panorex CMT plus with the same skull. Once the Panorex CMT plus was installed, many images of the dry skull were taken to find the settings which produced the clearest images. These results were found with a setting of a very small frame size while using 
three filters to compensate for lack of soft tissue. This information on the skull was entered into the computer database under a file named skull. When ready to image the skull, the file was opened. "Sinus/ Nasal Cavity" radiograph was selected from the radiographic menu. Unlike the Tomax Ultrascan, the Panorex CMT plus does not have a stationary body that can be used to line up the scribe line on the skull with the machine. To ensure accuracy in position, the skull was measured from porion to the scribe line distal to the maxillary right canine. This measurement was entered as the Y coordinate and 0 was entered as the $\mathrm{X}$ coordinate. This is opposite of the coordinates for the Tomax Ultrascan . These X, Y coordinates serve as the position of the ANC slice, $10 \mathrm{~mm}$ distal to this on the $\mathrm{Y}$ coordinate was the position for the $\mathrm{MNC}$, and $10 \mathrm{~mm}$ distal to this on the Y coordinate was the position for the PNC.

The skull was positioned on to the chin platform and in the ear rods. A positioning beam that illuminates the Frankfurt horizontal plane was activated to determine the proper vertical position of the skull relative to the film cassette with $15 \mathrm{x} 30$ $\mathrm{cm}$ film. The skull was imaged. The images were traced and retraced as described in the Tomax Ultrascan skull study. This procedure was repeated twice at one week intervals. The skull was properly stored after each image.

\section{Human Study}

Approval of this study was obtained from the Institutional Review Board for the protection of human research subjects prior to initiating this project. (Appendix A) 
Twenty-three patients between the ages of 8-15 were recruited to participate in the study. Nineteen patients completed the three films. All patients included in the study were patients of the West Virginia University Department of Orthodontics who had a diagnosis of maxillary transverse deficiency that required the use of a rapid palatal expander. Participating patients signed an assent form and their parents signed an informed consent form prior to exposing the first set of tomograms. (Appendix A) All participants were paid \$20.00 upon the completion of the third set of tomograms.

\section{Appliance Design}

All patients included in the study required a minimum of $4 \mathrm{~mm}$ of expansion (16 turns). Subjects were treated by various providers and had differing type of expansion appliances and expansion schedules. (Banded or bonded hyrax expansion appliances were used)

\section{Radiographic Procedures}

Operation procedures for the Tomax Ultrascan and Panorex CMT plus used in the dry skull study were applied to the human study. Once a file was created for each subject, pretreatment tomograms, T1, were taken prior to beginning expansion. Shoes were removed to maintain consistent height of each patient when placed on the Tomax Ultrascan platform. The patient was positioned on the platform. The chin cup and ear rods were positioned to the patient while standing upright. The ala-tragus length was measured and was used as the basis for the $10 \mathrm{~mm}$ slices. The horizontal and vertical 
measurements along with the cephalostat's width measurement were recorded prior to starting the radiographic exposure. Three cross-sectional images at T1 were taken: ANC, MNC, and PNC.

Each patient's file was retrieved from the computer's database for the next series of tomograms taken immediately after active expansion, T2. The chin cup was positioned at the vertical and horizontal distances that were recorded at the T1 film and the patient was repositioned into the chin cup and the ear rods were seated. The horizontal, vertical and width measurements of the cephalostat for each patient's positioning were verified prior to taking the radiograph when using the Tomax Ultrascan. The last three cross-sectional images of the nasal cavity were taken three months after active expansion, T3. A total of nine cross-sectional tomographic images were taken of each subject: three images at each time interval, T1, T2, and T3.

The Panorex CMT plus machine was installed prior to taking the T3 films and most of the T2 films. The protocol that was established with the dry skull on the Panorex CMT plus was used for the human subjects again. Each patient's data was entered into the computer database in a file with the patient's name prior to their appointment. Based on the skull study, the frame size was entered as very small for each patient to decrease the $\mathrm{kVp}$ to 50. The ala-tragus length was measured and was used to determine the 10 mm intervals for the slices of the ANC. The patients stood upright on the floor and the machine was adjusted for height. Ear rods were placed in their ears and a chin platform was moved up to the level of their chin. A positioning beam was then activated to show the Frankfurt Horizontal Plane. Once this was on the Frankfurt Horizontal Plane, the patient was in the correct position relative to the machine. "Sinus/Nasal Cavity" 
radiograph was selected from the menu, next "sinus" view was chosen. The length of the ala-tragus measurement was entered as the $\mathrm{Y}$ coordinate for the first slice (ANC), $\mathrm{X}$ coordinate was 0 . The next slice (MNC) was set for $10 \mathrm{~mm}$ distal to the first slice, and the last slice (PNC) was $10 \mathrm{~mm}$ distal to the second slice. The patient was imaged.

\section{Method of Measurement}

All left and right nasal cavities on the tomograms were traced on matte acetate paper with a $0.5 \mathrm{~mm}$ lead mechanical pencil. These images were retraced using a permanent ultra-fine Sharpie marker for better scanning visualization. The images on the acetate paper were scanned by the Epson Expression 1680 Scanner and saved in the orthodontic shared H drive in Dr. Palaisa’s folder labeled Scans.

The scans were imported into AutoCAD LT 2005 software as a raster image and retraced by clicking on the mouse repeatedly around the image. The shape was recreated by AutoCAD with lines drawn from the points specified by the mouse. Once the shape was drawn, the shape was highlighted by right clicking. The shape was verified to be the same as the original scanned in image. The area measurement (in cm squared) was calculated automatically and was listed under properties. Each tomogram had six areas recorded (e.g. At T1- LANC, RANC, LMNC, RMNC, LPNC, and RPNC). From the area measurements, the volumes were calculated in $\mathrm{cm}^{3}$ using the following formulas. 


\title{
Tomax Ultrascan Volume Calculations:
}

\author{
Volume $(\mathrm{V})=$ ANC $(0.1 \mathrm{~cm}+0.5 \mathrm{~cm})+\operatorname{MNC}(0.5 \mathrm{~cm}+0.1 \mathrm{~cm}+0.5 \mathrm{~cm})+\operatorname{PNC}(0.5$ \\ $\mathrm{cm}+0.1 \mathrm{~cm})$ \\ $=\operatorname{ANC}(0.6 \mathrm{~cm})+\mathrm{MNC}(1.1 \mathrm{~cm})+\mathrm{PNC}(0.6 \mathrm{~cm})$ \\ $0.1 \mathrm{~cm}$ is the thickness of the tomographic slice $(1 \mathrm{~mm})$ \\ $0.5 \mathrm{~cm}$ is the distance between the tomographic slices $(5 \mathrm{~mm})$
}

\section{Panorex CMT plus Calculations:}

Volume $(\mathrm{V})=$ ANC $(0.2 \mathrm{~cm}+0.5 \mathrm{~cm})+\operatorname{MNC}(0.5 \mathrm{~cm}+0.2 \mathrm{~cm}+0.5 \mathrm{~cm})+\operatorname{PNC}(0.5 \mathrm{~cm}$

$+0.2 \mathrm{~cm})$

$=\operatorname{ANC}(0.7 \mathrm{~cm})+\operatorname{MNC}(1.2 \mathrm{~cm})+\operatorname{PNC}(0.7 \mathrm{~cm})$

$0.2 \mathrm{~cm}$ the thickness of the tomographic slice $(2 \mathrm{~mm})$

$0.5 \mathrm{~cm}$ is the distance between the tomographic slices ( $5 \mathrm{~mm}$ ) 


\section{Statistical Analysis}

The data was compiled in an Excel Spreadsheet and given to Dr. Erdogan Gunel, a statistician, for analysis of the data. JMP statistical software was used. The reliability of the skull to be repositioned by the operator and traced in a repeatable manner on the old machine and new machine was tested by analyzing the area measurements (Appendix B) taken from the films using paired correlations and Cronbach's Alpha tests. The tracings of the skull from both machines were compared to each other with the same statistical tests to see if the operator produced reliable results with either machine. The

left, right and total areas and volumes were compared using paired t-tests. The level of significance was $\mathrm{p}<0.05$ (Appendix C)

\section{Equipment and Materials}

Tomax Ultrascan machine (Incubation Industries Inc., Ivyland, PA)

Panorex CMT plus machine ((Imagine Sciences International, Inc.)

AutoCAD LT 2005 software

5 inch by 12 inch radiographic film for tomograms

15 x $30 \mathrm{~cm}$ radiographic film for tomograms

JMP Statistical software

Microsoft Word

Cephalometric Viewbox

Cephalometric Acetate film and protractor 
Epson Expression 1680 Scanner 


\section{CHAPTER IV -RESULTS AND DISCUSSION}

\section{Results}

1. Reliability in positioning and tracing images in skull study on Tomax Ultrascan at times T1, T2 and T3.

2. Reliability in positioning and tracing images in skull study on Panorex CMT plus at times T1, T2 and T3

3. Reliability in reproducing skull images on the Tomax Ultrascan and Panorex CMT plus by comparing the images from the two machines.

4. Comparison of the area changes in the left anterior, middle and posterior nasal cavity at T1, T2 and T3.

5. Comparison of the area changes in the right anterior, middle and posterior nasal cavity at $\mathrm{T} 1, \mathrm{~T} 2$ and $\mathrm{T} 3$.

6. Comparison of total area changes (left and right) of the anterior, middle and posterior nasal cavities at T1, T2 and T3.

7. Comparison of changes in the area of the left versus the right nasal cavities.

8. Total volume changes of the nasal cavity from T1, T2 and T3.

\section{Reliability in positioning and tracing the images on the Tomax Ultrascan}

A cadaver skull was imaged at one week intervals for three weeks. The skull's nasal cavity images were traced onto acetate paper and scanned into a computer. AutoCad LT 2005 software was used to calculate the areas of the LANC, RANC, LMNC, RMNC, LPMC and RPNC from the three films of the skull. The new data can be found in Appendix B. 
Pairwise correlations of the measured areas from $\mathrm{T} 2$ to $\mathrm{T} 1$ were 0.85 , from $\mathrm{T} 3$ to T1 were 0.96 and from T3 to T2 were 0.95. Using the Cronbach’s Alpha test, the areas of the entire data set was found to have a correlation of 0.97. (Values of correlation above 0.7 are considered to be statistically significant.) These data suggest that the operator was very reliable at repositioning the skull and tracing the images from the films.

\section{Reliability in Positioning and Tracing the images on the Panorex CMT plus}

On the Panorex CMT plus machine, the same skull was imaged at one week intervals for three weeks. The images were traced and scanned into the computer and AutoCAD LT 2005 software was used to calculate the areas of LANC, RANC, LMNC, RMNC, LPNC and RPNC from the images taken of the skull. The new data can be found in Appendix B.

The area calculations from the three films were compared. From the film taken on the Panorex CMT plus, the areas from time T2 correlated to time $\mathrm{T} 1$ by 0.98 . Time T3 to time T1 was 0.99 and time $\mathrm{T} 3$ to time T2 was 0.99 . Using the Cronbach's Alpha test, the area measurements for T1, T2 and T3 were found to have a correlation of 0.99. (Values of correlation above 0.7 are considered to be statistically significant). Therefore, the

operator was very reliable in positioning the skull, tracing the images from the films and measuring the areas of the nasal cavity from the skull. 


\section{Reliability in reproducing skull images on the Tomax Ultrascan and Panorex CMT plus by comparing the images from the two machines}

The area measurements of the nasal cavities imaged on the Tomax Ultrascan at times T1, T2 and T3 were averaged and compared to the Panorex CMT plus measurements of nasal cavity areas at times T1, T2 and T3. Pairwise correlations and the Cronbach's Alpha test of these measurements found that the images taken from the two machines were highly correlated (0.99). The area measurements can be found in Appendix B.

\section{Comparison of the area changes in the left anterior, middle and posterior nasal cavity at $\mathrm{T} 1, \mathrm{~T} 2$ and $\mathrm{T} 3$}

The areas of the left anterior, middle and posterior nasal cavities were averaged for all patients for the time periods T1, T2, and T3. The new data can be found in Appendix B. These values were used to calculate the differences or changes in areas of the nasal cavity from time $\mathrm{T} 1$ to time $\mathrm{T} 2$, from time $\mathrm{T} 2$ to time $\mathrm{T} 3$ and from time $\mathrm{T} 1$ to T3. Paired t-tests were used to test the significance of the changes in area at these different time intervals. All mean areas were found to increase significantly using a confidence level of $\mathrm{p}<0.05$. From time T1 to T3 the LANC increased 39.6\%, LMNC increased 37.7\% and the LPNC increased 36.6\%. The results are shown in TABLE 1. 


\begin{tabular}{|c|c|c|c|c|}
\hline $\begin{array}{c}\text { Area of Left } \\
\text { Nasal Cavity }\end{array}$ & \multicolumn{2}{c|}{ Time Interval } & $\begin{array}{c}\text { Area Changes } \\
\mathbf{( c m}^{\mathbf{2}} \mathbf{n}\end{array}$ & \multicolumn{2}{c|}{$\begin{array}{c}\text { Standard } \\
\text { Deviation }\end{array}$} & P value \\
\hline LANC & T2-T1 & 0.44 & 0.74 & $<0.009$ \\
\hline LANC & T3-T2 & 1.02 & 0.9 & $<0.0001$ \\
\hline LANC & T3-T1 & 1.46 & 1.14 & $<0.0001$ \\
\hline LMNC & T2-T1 & 0.52 & 0.69 & $<0.002$ \\
\hline LMNC & T3-T2 & 1.12 & 0.6 & $<0.0001$ \\
\hline LMNC & T3-T1 & 1.64 & 0.71 & $<0.0001$ \\
\hline LPNC & T2-T1 & 0.67 & 0.7 & $<0.0003$ \\
\hline LPNC & T3-T2 & 0.97 & 0.97 & $<0.0002$ \\
\hline LPNC & T3-T1 & 1.64 & 0.92 & $<0.0001$ \\
\hline
\end{tabular}

Table 1: Mean changes in left anterior, middle and posterior nasal cavities from T1, T2 and T3, $\mathbf{p}<\mathbf{0 . 0 5}$

\section{Comparison of the area changes in the Right Anterior, middle and posterior nasal cavity at $\mathrm{T} 1, \mathrm{~T} 2$ and $\mathrm{T} 3$.}

The areas of the right anterior, middle and posterior nasal cavities were averaged for all patients for the time periods $\mathrm{T} 1, \mathrm{~T} 2$ and $\mathrm{T} 3$. The new data can be found in Appendix B. These values were used to calculate the differences or changes in areas of the nasal cavity from time $\mathrm{T} 1$ to time $\mathrm{T} 2$, from time $\mathrm{T} 2$ to time $\mathrm{T} 3$ and from Time $\mathrm{T} 1$ to T3. Paired t-tests were used to test the significance of the changes in area from these different time intervals. All mean areas were found to increase significantly using a confidence level of $\mathrm{p}<0.05$, except for the RMNC changes from time T2 to time T1. From time $\mathrm{T} 1$ to $\mathrm{T} 3$ the RANC increased 32.5\%, the RMNC increased 35.7\%, and the RPNC increased 32.9\%. The results are shown in TABLE 2. 


\begin{tabular}{|c|c|c|c|c|}
\hline $\begin{array}{c}\text { Area of Right } \\
\text { Nasal Cavity }\end{array}$ & Time Interval & $\begin{array}{c}\text { Area Changes } \\
\left(\mathbf{c m}^{\mathbf{2}}\right)\end{array}$ & $\begin{array}{c}\text { Standard } \\
\text { Deviation }\end{array}$ & P value \\
\hline RANC & T2-T1 & 0.41 & 0.5 & $<0.0011$ \\
\hline RANC & T3-T2 & 0.76 & 0.5 & $<0.0001$ \\
\hline RANC & T3-T1 & 1.17 & 0.75 & $<0.0001$ \\
\hline RMNC & T2-T1 & 0.29 & 0.77 & $<0.06 *$ \\
\hline RMNC & T3-T2 & 1.28 & 0.76 & $<0.0001$ \\
\hline RMNC & T3-T1 & 1.57 & 0.76 & $<0.0001$ \\
\hline RPNC & T2-T1 & 0.46 & 1.0 & $<0.036$ \\
\hline RPNC & T3-T2 & 1.03 & 0.94 & $<0.0001$ \\
\hline RPNC & T3-T1 & 1.49 & 1.08 & $<0.0001$ \\
\hline
\end{tabular}

Table 2: Mean changes in the right anterior, middle, and posterior nasal cavities from T1, T2 and T3 , $\mathbf{p}<0.05$

*area changes in the RMNC from time T1 to time T2 were not significant

\section{Comparison of total area changes (left and right) of the anterior, middle and posterior nasal cavities at $\mathrm{T} 1, \mathrm{~T} 2$ and $\mathrm{T} 3$}

The areas of the left and right anterior, middle and posterior nasal cavities were added together and averaged to find the total area of the anterior nasal cavity for each patient for the time periods T1, T2, and T3. The new data can be found in Appendix B. These numbers were used to measure the total area changes in the nasal cavity from time T1 to T2, from T2 to T3 and from T1 to T3. All areas of the nasal cavity were found to increase significantly from time T1 to time T2 and time T3 using a confidence level of $\mathrm{p}<0.05$. From time $\mathrm{T} 1$ to $\mathrm{T} 3$ the total area of the ANC increased $36 \%$, the total area of the MNC increased 36.6\%, and the total area of the PNC increased 35\%. The results are shown in TABLE 3. 


\begin{tabular}{|c|c|c|c|c|}
$\begin{array}{c}\text { Total area } \\
\text { change of } \\
\text { Nasal Cavity }\end{array}$ & Time Interval & $\begin{array}{c}\text { Area Changes } \\
\left(\mathbf{c m}^{\mathbf{2}}\right)\end{array}$ & \multicolumn{2}{c|}{$\begin{array}{c}\text { Standard } \\
\text { Deviation }\end{array}$} \\
ANC & T2-T1 & 0.85 & 1.2 & P value \\
\hline ANC & T3-T2 & 1.78 & 1.2 & $<0.003$ \\
\hline ANC & T3-T1 & 2.63 & 1.74 & $<0.001$ \\
\hline MNC & T2-T1 & 0.81 & 1.36 & $<0.0001$ \\
\hline MNC & T3-T2 & 2.4 & 1.03 & $<0.0001$ \\
\hline MNC & T3-T1 & 3.2 & 1.2 & $<0.0001$ \\
\hline PNC & T2-T1 & 1.13 & 1.6 & $<0.0033$ \\
\hline PNC & T3-T2 & 2.05 & 1.85 & $<0.0001$ \\
\hline PNC & T3-T1 & 3.18 & 1.68 & $<0.009$ \\
\hline
\end{tabular}

Table 3: Mean area changes of the right and left (total area changes) anterior, middle, and posterior nasal cavities at time $\mathrm{T} 1, \mathrm{~T} 2$, and $\mathrm{T} 3, \mathrm{p}<0.05$

\section{Comparison of changes in the area of the Left versus the Right nasal cavities}

The left and right nasal cavities were measured at times T1, T2 and T3. All of the patient's right ANC areas were added and averaged to get a value for RANC at time T1, RANC and time T2 and RANC at time T3. The same was done for the RMNC, RPNC, LANC, LMNC, and LPNC. The new data can be found in Appendix B. These average values were used to find changes in the right vs. left nasal cavity at the three different times. For example, the changes in area from time $\mathrm{T} 1$ to time $\mathrm{T} 2$ in the RANC vs. LANC were $0.03 \mathrm{~mm}$ with a SD of 0.09 , prob $<0.71$. There were no significant differences in the changes in area in the left vs. right nasal cavities at time T1, T2 or T3 at a confidence level of $\mathrm{p}<0.05$. The results are shown in TABLE 4 . 


\begin{tabular}{|c|c|c|c|c|}
\hline $\begin{array}{c}\text { Area changes } \\
\text { of the left } \\
\text { versus right } \\
\text { nasal cavity }\end{array}$ & Time Interval & $\begin{array}{c}\text { Area Changes } \\
\left(\mathrm{cm}^{2}\right)\end{array}$ & $\begin{array}{l}\text { Standard } \\
\text { Deviation }\end{array}$ & P value \\
\hline RANC-LANC & T2-T1 & -0.03 & 0.09 & $<0.64^{*}$ \\
\hline RANC-LANC & T3-T2 & -0.26 & 0.18 & $<0.91 *$ \\
\hline RANC-LANC & T3-T1 & -0.3 & 0.19 & $<0.93 *$ \\
\hline RMNC-LMNC & $\mathrm{T} 2-\mathrm{T} 1$ & 0.13 & 0.03 & $<0.96 *$ \\
\hline RMNC-LMNC & T3-T2 & 0.15 & 0.2 & $<0.22 *$ \\
\hline RMNC-LMNC & T3-T1 & -0.07 & 0.18 & $<0.66^{*}$ \\
\hline RPNC-LPNC & T2-T1 & -0.21 & 0.18 & $<0.88 *$ \\
\hline RPNC-LPNC & T3-T2 & 0.06 & 0.16 & $<0.36 *$ \\
\hline RPNC-LPNC & T3-T1 & -0.15 & 0.2 & $<0.77 *$ \\
\hline
\end{tabular}

Table 4: Comparison of changes in the mean areas of the left versus right nasal cavities at $\mathrm{T} 1, \mathrm{~T} 2$ and T3, $\mathrm{p}<0.05$

* area changes are not significant

There were significant changes in the right areas and left areas of the nasal cavity from the different time intervals. See Table 5 for details.

\begin{tabular}{|c|c|c|c|c|}
\hline Area Changes & Time Interval & $\begin{array}{c}\text { Area changes } \\
\left.\text { (cm }^{2}\right)\end{array}$ & $\begin{array}{c}\text { Standard } \\
\text { Deviation }\end{array}$ & P value \\
\hline RNC & T2-T1 & 0.84 & 1.36 & $<0.036$ \\
\hline RNC & T3-T2 & 2.48 & 1.41 & $<0.0001$ \\
\hline RNC & T3-T1 & 3.31 & 1.45 & $<0.0001$ \\
\hline LNC & T2-T1 & 1.24 & 1.45 & $<0.0008$ \\
\hline LNC & T3-T2 & 2.43 & 1.25 & $<0.0001$ \\
\hline LNC & T3-T1 & 3.67 & 1.38 & $<0.0001$ \\
\hline
\end{tabular}

Table 5: Mean Area changes in the right and the left nasal cavities at times T1, T2, and T3, $\mathbf{p}<0.05$ 


\section{Total volume changes of the nasal cavity from T1, T2 and T3}

The volume was calculated for the entire nasal cavity at time T1, T2 and T3. These values were calculated for each patient, added and averaged to get values for T1, T2 and T3. The new data can be found in Appendix B. The differences in the volume at time T2 from T1, T3 from T2 and T3 from T1 were compared. The volume was found to increase significantly from time T1 to time T2 (10.7\%) and to time T3 (27.8\%) with a confidence level of $\mathrm{p}<0.05$. The results are shown in Table 6 .

\begin{tabular}{|c|c|c|c|}
$\begin{array}{c}\text { Volume changes of } \\
\text { the Nasal Cavity }\end{array}$ & $\begin{array}{c}\text { Mean Volume } \\
\text { Changes } \mathbf{( c m}^{\mathbf{3}} \mathbf{)}\end{array}$ & $\begin{array}{c}\text { Standard } \\
\text { Deviation }\end{array}$ & P value \\
\hline T2-T1 & 2.08 & 2.66 & $<0.0016$ \\
\hline T3-T2 & 4.9 & 2.3 & $<0.0001$ \\
\hline T3-T1 & 6.99 & 2.45 & $<0.0001$ \\
\hline
\end{tabular}

Table 6: Total Volume Changes in the Nasal Cavity from T1, T2 and T3

\section{Discussion}

To date, there are no studies published examining the anatomical changes in area and volume of the nasal cavity after Rapid Palatal Expansion using conventional tomography. Multiple studies have been completed assessing the stability of maxillary width, changes in the transverse plane and nasal structures using PA cephalograms, occlusal films and/or dental casts.(55-57) In one study, computed tomography was used to measure the nasal airway of one patient after RPE.(16) Despite being very accurate at measuring the area and volume of the nasal cavity, computed tomography is not practical due to its expense and the amount of radiation involved.(16;46;47) Conventional tomography is more cost effective and can provide similar diagnostic information.(49) 
According to pairwise correlations of data from this study, the imaging technique used on the skull using conventional tomography was a reliable method to produce repeatable images of the nasal cavity. The area measurements from the skull images on the Tomax Ultrascan at time T1, T2 and T3 had a correlation of 0.97. The area measurements from the skull images on the Panorex CMT plus had a correlation of 0.99. These correlations demonstrate that the operator was very reliable in positioning, tracing and measuring the areas on the images. A comparison of the nasal cavity areas from the skull images produced on the Tomax Ultrascan and Panorex CMT plus showed that the images had a correlation of 0.99. The operator's reliability on the two machines was found to be comparable. (Appendix C)

This study involved tomograms from 19 patients taken at three different time periods. There were no individual patient comparisons done. As a group, there were significant increases in left, right and total area from the different time periods: T1 to T2, $\mathrm{T} 2$ to $\mathrm{T} 3$ and $\mathrm{T} 1$ to T3. The only exception was the right middle nasal cavity which showed no significant increases from time T1 to time T2. Although there are no published studies using conventional tomography to assess stability of the maxilla after RPE, there are studies using PA cephalograms to examine the stability of maxillary expansion. A study by Cameron(58) examined changes in maxillary width and maxillary first molar width by using skeletal and dental landmarks on PA cephalograms before expansion (T1) and an average of 8 years later (T2). The RPE removed 2 months after expansion but no radiograph was taken at that time. Cameron compared the changes between $\mathrm{T} 1$ and $\mathrm{T} 2$ to those changes normally found due to growth according to the University of Michigan Growth Studies. Cameron found that the maxillary width and 
maxillary first molar width exceeded the expected growth increment in the control group from the Michigan Growth Studies by $2.3 \mathrm{~mm}$ on an average of 8 years later (mean age of 20). A prospective study by Memikoglu (59) examined changes in the transverse plane following bonded RPE (5.5-6.5 mm of expansion) and fixed therapy. Using PA cephalograms and dental casts of pre-treatment, post-expansion and post-treatment results, Memikoglu measured skeletal and dental reference points and found that there is an increase in transverse linear measurements after expansion and these changes are maintained and sometimes increase by the end of conventional orthodontic treatment. During his study, there was no relapse after RPE and fixed therapy. Cross (60) also used PA cephalograms to compare the transverse dimension of skeletal, dental, and nasal structures of a group before and after RME to a group of untreated patients. Cross found that RPE produced a small (maximum linear width of the nasal cavity increased by a mean distance of $1.06 \mathrm{~mm}$ ) but, statistically significant changes in the maxillary width and intranasal width but there is some evidence that the pattern of expansion varies depending on age and maturity of the subject. His treatment group consisted of 20 females and 5 males and could have reflected a difference in sex ratio since females mature earlier than males and this can resist the forces of expansion. He also found that the maxillary width as measured from $\mathrm{mx}$ to $\mathrm{mx}$ increased by a mean of 1.11 with a SD of 1.41. He concluded that the large standard deviation reflects the variation in individuals due to RPE. Hershey (61)performed a study using dental casts, PA cephalograms and NAR readings on patients who received RPE as part of their treatment. The authors used linear measurements and compared radiographs and models from before expansion (T1), immediately after expansion (T2) and three months later (T3). 
The authors found that the nasal cavity width increased from time T1 to time T2 by 2.03 $\mathrm{mm} \pm 0.81$ and this width actually increased during retention by $0.33 \mathrm{~mm} \pm 0.34$ (T3). In contrast, Krebs(13) used metallic implants and frontal cephalometric radiographs and showed that the initial increase in width of the nasal cavity narrowed from $2.5 \mathrm{~mm}$ to 2.0 mm during two months of retention. With the exception of the study by Krebs (13), all of these studies had conclusions that support the results of the current study although none of the previous studies measured area changes associated with RPE.

A study on 40 patients using occlusal films after RPE by Thorn(45) found an initial increase in nasal width of $1.7 \mathrm{~mm}$ after treatment, but this gain was generally lost in retention. Moussa(62)evaluated the long-term stability of the dental arches of patients treated with RPE. He looked at 165 casts of patients who had completed treatment 8-10 years earlier and concluded that the expansion at the upper canines (net increase of 2.7 $\pm 2.8 \mathrm{~mm}$ ) and molars (net increase of $5.5 \pm 4.0 \mathrm{~mm}$ was stable. He did not measure the nasal width.

Although there are numerous studies using PA cephalograms and occlusal films to assess changes in maxillary and nasal width, Vig cautioned against using PA cephalograms to assess changes in the nasal airway since they can only show one plane.(16) Occlusal films can only show one plane as well. Vig (16) reported the results of one patient treated with RPE who was imaged using computed tomography and found there remained an increase post-expansion in the anterior region but little to no change in the back of the nose. The conflicts in data among the studies could be due to the limitations of using PA cephalograms and occlusal films and linear measurements or due to individual variation or, in Vig's case, a limited patient pool. 
Conventional tomography was used to assess nasal septal deviation after surgically assisted RPE in a study by Schwarz(63) He examined nine patients for septal deviation using four coronal tomograms that were taken within four months after surgical intervention. Linear measurements and the areas of the right and left airway spaces were recorded and compared to post-treatment measurements. Significant increases in available nasal airway were found (total mean area of left and right nasal airway pretreatment was $61.79 \mathrm{~mm}^{2}$ and post-treatment was $101.09 \mathrm{~mm}^{2}$ ), but the mechanism was unknown. He speculated that it could be from expansion of the lateral nasal walls but could find no evidence to support this and he concluded it might be due to tissue shrinkage.

Many studies have found a decrease in NAR after RPE.(7;29;64-71), but the stability of the NAR reduction has had conflicting results . Hershey(72) and White (73) studied the decrease in NAR after RPE. Both found that the reduction in NAR was stable over time (45\% reduction in NAR present 3 months later (21) and 48.7\% reduction of NAR present one year later(22)). Ngan(74)found that orthopedic treatment directed at the maxilla in Class III malocclusions is stable despite some relapse (30-45\% relapse after one year). On the other hand, a study by Wertz(7) studied the effects of RPE on NAR and found inconclusive results that could not justify palatal expansion for the improvement of nasal air resistance. Individual variations in patients could be the cause of the controversial results in the NAR studies.

There were significant increases in the total volume from time T1 to T2, time T2 to time T3 and time T1 to time T3. Increases in volume of the nasal cavity would support the studies that demonstrated a reduction in NAR after expansion.(75) Volumetric data 
gives a good indication of overall expansion and relapse, but does not give any information concerning expansion in different parts of the nasal cavity. (17)

There were no significant differences in the changes in the left versus the right nasal cavity in any of the measurements (areas of ANC, MNC, PNC, and total area) at the different time intervals. This finding was supported by a study by Bell (1982) that discussed the variability in the pattern of expansion depending on the patients age and maturity level (76) and by multiple cephalometric studies that show that the sutural separation of the maxilla is non-uniform. (3;37-41). Asanza (1997) found that the changes in expansion are not symmetrical and that the expansion varied from left to right and varied in different individuals.(19) 


\section{CHAPTER V -SUMMARY AND CONCLUSIONS}

\section{Summary}

The purpose of this study was to use conventional tomography to determine the anatomical changes within the nasal cavity following rapid palatal expansion. A dry skull study was performed on the Tomax Ultrascan and the Panorex CMT plus to establish the parameters for the use of these machines prior to the human study and to compare the two machines for consistency. Positioning and tracing errors by the operator were analyzed by comparing all of the tomograms from both machines at all times. All images were highly correlated (0.99)

The human study consisted of 19 patients between the ages of 8 and 15 years old treated at West Virginia University School of Dentistry Department of Orthodontics. All patients were diagnosed with a maxillary transverse deficiency that required the use of a rapid palatal expander. Participants in the study had various types of skeletal expanders. A total of nine cross-sectional tomograms were taken of each patient. Three crosssectional images (ANC, MNC, and PNC) taken at three different time periods; pretreatment, T1, immediately following active expansion, $\mathrm{T} 2$, and three months following expansion, T3.

The data was analyzed using correlations, Cronbach's alpha tests, and paired ttests to determine the statistically significant differences among the different time intervals as well as the differences among the cross-sectional images. 


\section{Conclusions}

The use of conventional tomography proved to be helpful in viewing a threedimensional object such as the nasal cavity. The images allowed assessment of the height and width changes of the nasal cavity along with changes in depth. In contrast to frontal P-A radiographs, cross-sectional images can be made along the length of the nasal airway with the use of tomograms. This allowed for comparison of the anterior nasal cavities, middle nasal cavities and posterior nasal cavities.

The results of this study include:

\section{Comparison of Left Anterior, Middle, and Posterior Nasal cavity at T1, T2 and T3.}

1. Significant increases in area were found immediately following active expansion for anterior, middle and posterior nasal cavity.

2. Significant increases in area were found immediately following active expansion and three months following active expansion for anterior, middle and posterior nasal cavity.

3. Significant increases in area were found between pretreatment and three months following active expansion for anterior, middle, and posterior nasal cavity.

\section{Comparison of Right Anterior, Middle, and Posterior Nasal Cavity at T1, T2, and T3}

1. Significant increases in area were found immediately following active expansion for the anterior and posterior nasal cavity. 
2. No significant increase in area was found in the right middle nasal cavity between pretreatment and active expansion.

3. Significant increases in area were found immediately following active expansion and three months following active expansion for the anterior, middle and posterior nasal cavity.

4. Significant increases in area were found between pre-treatment and three months following active expansion for anterior, middle, and posterior nasal cavity.

\section{Comparison of total area changes (left and right) of the anterior, middle, and posterior nasal cavities at time $\mathrm{T} 1, \mathrm{~T} 2$, and $\mathrm{T} 3$}

1. There were significant increases in the total area found immediately following active expansion for anterior, middle and posterior nasal cavity.

2. Significant increases in area found immediately following active expansion and three months following active expansion for anterior, middle and posterior nasal cavity.

3. Significant increases in area were found between pretreatment and three months following active expansion for anterior, middle, and posterior nasal cavity.

\section{Comparison of changes in the area of the left versus the right nasal cavity}

1. No significant differences in mean area changes were found between the left or right nasal cavity were found immediately following active expansion for the anterior, middle or posterior nasal cavity. 
2. No significant differences in mean area changes were found between the left or right nasal cavity were found immediately following active expansion and three months following active expansion for the anterior, middle, or posterior nasal cavity.

3. No significant differences in mean area changes were found between the left or right nasal cavity were found between pretreatment and three months following active expansion for the anterior, middle or posterior nasal cavity.

\section{Total volume changes of the nasal cavity from $\mathrm{T} 1, \mathrm{~T} 2$, and $\mathrm{T} 3$}

1. Significant increases in volume were found immediately following active expansion for the left and right nasal cavity.

2. Significant increases in volume were found immediately following active expansion and three months following active expansion for the left and right nasal cavity.

3. Significant increases in volume were found between pretreatment and three months following active expansion for the left and right nasal cavity.

In summary, conventional tomography was effective in evaluating the nasal cavity. It allowed for assessment of the nasal cavity in the transverse, vertical and sagittal dimension. Unlike frontal P-A radiographs, cross-sectional images can be made along the length of the nasal airway with the use of tomograms. It was determined that the area and volume increases significantly in all areas of the nasal cavity except for the right middle nasal cavity from pretreatment to immediately after 
expansion. There appeared to be no relapse during the retention phase of three months after active expansion. In fact, the areas and volumes increased significantly for all parts of the nasal cavity immediately after expansion until three months later. These results support previous studies that show continued reduction in NAR and airway obstruction symptoms long after the completion of expansion.

\section{Future Research}

Future research could evaluate a fourth time interval on the same patients (T4) at the end of comprehensive orthodontic treatment to see if the changes in the nasal cavity are still stable. Another study that might be of value could evaluate the changes in nasal airway resistance after RPE and the way this correlates to changes in the area and volume of the nasal cavity. In the very near future the study could be repeated on the three- dimensional tomography machine which is going to be purchased by our program. This machine could easily be used to accurately image the nasal cavity and determine the area and volume with much less chance for error than the method described in this study. 


\section{REFERENCE LIST}

1. Pfaff W. Stenosis of the Nasal Cavity by Contraction of the Palatal Arch and Abnormal Position of the Teeth. Dental Cosmos 1905; 47: 570-3.

Ref ID: 4

2. Brown GVI. The Application of Orthodontia Principles to the Prevention of Nasal Disease. Dental Cosmos 1903; 45: 765-75.

Ref ID: 39

3. Haas AJ. Rapid Expansion of the Maxillary Dental Arch and Nasal Cavity by Opening the Midpalatal Suture. Angle Orthod 1961; 31: 73-90.

Ref ID: 40

4. Brogan WF. The stability of maxillary expansion. Aust Dent J 1977; 22: 92-9. Ref ID: 15

5. Gray LP. Septal deformity malocclusion and rapid maxillary expansion. Orthodontist 1972; 4: 2-14.

Ref ID: 41

6. Black NM. The relation between deviation of nasal septum and irregularities of the teeth and jaw. JAMA 1909; 52: 943-5.

Ref ID: 42

7. Wertz RA. Changes in nasal airflow incident to rapid maxillary expansion. Angle Orthod 1968; 38: 1-11.

Ref ID: 43

8. Gray LP. Rapid maxillary expansion and impaired nasal respiration. Ear Nose Throat J 1987; 66: 248-51.

Ref ID: 30

9. Timms DJ. The reduction of nasal airway resistance by rapid maxillary expansion and its effect on respiratory disease. J Laryngol Otol 1984; 98: 357-62. Ref ID: 34

10. Angell EC. Treatment of Irregularities of Permanent or Adult Teeth. Dental Cosmos 1890; 1: 540-4-599-600.

Ref ID: 44

11. Lohman A. Treatment of Narrow Nasal Passages. Register 1916; 70: 14-6. Ref ID: 45 
12. Derichsweiler H. Die Gaumenrahtsprengung. Band 1953; 14.

Ref ID: 46

13. Krebs A. Expansion of the midpalatal suture studied by means of metallic implants. Europ Orthod Soc Report 1958; 34: 163-71.

Ref ID: 47

14. Wright GH. A Group of Deformities of the Nasal Respiratory Tract, Coincident with Dental Irregularities II. A New Instrument for Comparative Measurements. Dental Cosmos 1912; 54: 261-9.

Ref ID: 48

15. Derichsweiler H. La Disjonction de la Suture Palatine medane. Trans European Orthodont Soc 1953.

Ref ID: 49

16. Vig PS. Nasorespiratory Function and Craniofacial growth. 1979.

Ref ID: 50

17. Tran, A. Use of Conventional Tomography to Evaluate Changes in the Nasal Cavity with Rapid Palatal Expansion. 1997.

Ref Type: Thesis/Dissertation

Ref ID: 68

18. Schwarz GM, Thrash WJ, Byrd DL, Jacobs JD. Tomographic assessment of nasal septal changes following surgical-orthodontic rapid maxillary expansion. Am J Orthod 1985; 87: 39-45.

Ref ID: 13

19. Asanza S, Cisneros GJ, Nieberg LG. Comparison of Hyrax and bonded expansion appliances. Angle Orthod 1997; 67: 15-22.

Ref ID: 26

20. Reed N, Ghosh J, Nanda RS. Comparison of treatment outcomes with banded and bonded RPE appliances. Am J Orthod Dentofacial Orthop 1999; 116: 31-40. Ref ID: 21

21. Bicakci, A. and Agar U.et al. Nasal Airway Changes Due to Rapid Maxillary Timing. Angle Orthod. 75, 1-6. 2005.

Ref Type: Generic

Ref ID: 73

22. Hershey HG, Stewart BL, Warren DW. Changes in nasal airway resistance associated with rapid maxillary expansion. Am J Orthod 1976; 69: 274-84.

Ref ID: 16 
23. White BC, Woodside DG, Cole P. The effect of rapid maxillary expansion on nasal airway resistance. J Otolaryngol 1989; 18: 137-43.

Ref ID: 2

24. Gray LP. Results of 310 cases of rapid maxillary expansion selected for medical reasons. J Laryngol Otol 1975; 89: 601-14.

Ref ID: 17

25. Gray LP. Rapid maxillary expansion and impaired nasal respiration. Ear Nose Throat J 1987; 66: 248-51.

Ref ID: 30

26. Palmisano RG, Wilcox I, Sullivan CE, Cistulli PA. Treatment of snoring and obstructive sleep apnoea by rapid maxillary expansion. Aust N Z J Med 1996; 26: 428-9.

Ref ID: 27

27. Cistulli PA, Palmisano RG, Poole MD. Treatment of obstructive sleep apnea syndrome by rapid maxillary expansion. Sleep 1998; 21: 831-5.

Ref ID: 24

28. Hershey HG, Stewart BL, Warren DW. Changes in nasal airway resistance associated with rapid maxillary expansion. Am J Orthod 1976; 69: 274-84.

Ref ID: 16

29. Turbyfill, W. J. The long-term effect of rapid maxillary expansion. 1976.

Ref Type: Thesis/Dissertation

Ref ID: 51

30. Hartgerink DV, Vig PS, Abbott DW. The effect of rapid maxillary expansion on nasal airway resistance. Am J Orthod Dentofacial Orthop 1987; 92: 381-9.

Ref ID: 9

31. White BC, Woodside DG, Cole P. The effect of rapid maxillary expansion on nasal airway resistance. $J$ Otolaryngol 1989; 18: 137-43.

Ref ID: 2

32. Timms DJ. The reduction of nasal airway resistance by rapid maxillary expansion and its effect on respiratory disease. J Laryngol Otol 1984; 98: 357-62. Ref ID: 34

33. Timms DJ. Rapid maxillary expansion in the treatment of nasal obstruction and respiratory disease. Ear Nose Throat J 1987; 66: 242-7.

Ref ID: 31

34. Warren DW, Hershey HG, Turvey TA, Hinton VA, Hairfield WM. The nasal airway following maxillary expansion. Am J Orthod Dentofacial Orthop 1987; 
91: 111-6.

Ref ID: 32

35. Basciftci FA, Mutlu N, Karaman AI, Malkoc S, Kucukkolbasi H. Does the timing and method of rapid maxillary expansion have an effect on the changes in nasal dimensions? Angle Orthod 2002; 72: 118-23.

Ref ID: 5

36. Basciftci FA, Mutlu N, Karaman AI, Malkoc S, Kucukkolbasi H. Does the timing and method of rapid maxillary expansion have an effect on the changes in nasal dimensions? Angle Orthod 2002; 72: 118-23.

Ref ID: 5

37. Haas AJ. Just the beginning of Dentofacial Orthopedics. Am J Orthod 1970; 57: 219-55.

Ref ID: 53

38. Krebs A. Midpalatal suture expansiion studied by the implant method over a seven-year period. Trans European Orthodont Soc 1964; 131.

Ref ID: 54

39. Timms DJ. A study of basal movement with rapid maxillary expansion. Am J Orthod 1980; 77: 500.

Ref ID: 55

40. Wertz RA. Skeletal and Dental Changes Accompanying Rapid Midpalatal Suture Opening. Am J Orthod 1970; 58: 41-66.

Ref ID: 56

41. Bell RA. A review of maxillary expansion in relation to the rate of expansion and patient's age. Am J Orthod 1982; 81: 32-7.

Ref ID: 57

42. Cameron CG, Franchi L, Baccetti T, McNamara JA, Jr. Long-term effects of rapid maxillary expansion: a posteroanterior cephalometric evaluation. Am J Orthod Dentofacial Orthop 2002; 121: 129-35.

Ref ID: 18

43. Cross DL, McDonald JP. Effect of rapid maxillary expansion on skeletal, dental, and nasal structures: a postero-anterior cephalometric study. Eur J Orthod 2000; 22: 519-28.

Ref ID: 19

44. Memikoglu TU, Iseri $\mathbf{H}$. Effects of a bonded rapid maxillary expansion appliance during orthodontic treatment. Angle Orthod 1999; 69: 251-6.

Ref ID: 22 
45. Thorn NA. Expansion of Maxilla Spreading the Midpalatal Suture; Measuring the Widening of the Apical Base and the Nasal Cavity on Serial Roentgenograms. Am J Orthod 1960; 46: 626.

Ref ID: 52

46. Montgomery W. Computed Tomography: A Three-Dimensional Study of the Nasal Airway. Am J Orthod 1979; 76: 363-75.

Ref ID: 58

47. Montgomery W. Rapid Maxillary Expansion Effects on Nasal Cavity Computed Tomography Study. IADR 1979; 58: 1248.

Ref ID: 59

48. Clark DE. Radiation Absorbed from dental implant radiography: A comparison of linear tomography, CT scan, and panoramic and intra-oral techniques. J Oral Implantol 1990; 16: 156-64.

Ref ID: 61

49. Hamada MO. Implantology: radiographic resources. Journal of Calif Dent Assoc 1989; 17: 20-31.

Ref ID: 62

50. Eckerdal O. Presurgical planning for osseointegrated implants in the maxilla. A tomographic evaluation of available alveolar bone and morphological relations in the maxilla. Int J Oral Maxillofac Surg 1986; 15: 722-6.

Ref ID: 63

51. Curry TSDJEMRC. Christensen's Physics of Diagnostic Radiology. Fourth edn. 1990.

Ref ID: 64

52. Goaz PWWSC. Oral Radiology: Principles and Interpretation. 3rd edn. Mosby; 1994.

Ref ID: 65

53. Rosenberg HM. TMJ radiography with emphasis on tomography. Dent Rad and Photog 1982; 55: 1-24.

Ref ID: 67

54. Schwarz GM, Thrash WJ, Byrd DL, Jacobs JD. Tomographic assessment of nasal septal changes following surgical-orthodontic rapid maxillary expansion. Am J Orthod 1985; 87: 39-45.

Ref ID: 13

55. Cameron CG, Franchi L, Baccetti T, McNamara JA, Jr. Long-term effects of rapid maxillary expansion: a posteroanterior cephalometric evaluation. Am J Orthod Dentofacial Orthop 2002; 121: 129-35.

Ref ID: 18 
56. Memikoglu TU, Iseri $\mathbf{H}$. Effects of a bonded rapid maxillary expansion appliance during orthodontic treatment. Angle Orthod 1999; 69: 251-6.

Ref ID: 22

57. Cross DL, McDonald JP. Effect of rapid maxillary expansion on skeletal, dental, and nasal structures: a postero-anterior cephalometric study. Eur J Orthod 2000; 22: 519-28.

Ref ID: 19

58. Cameron CG, Franchi L, Baccetti T, McNamara JA, Jr. Long-term effects of rapid maxillary expansion: a posteroanterior cephalometric evaluation. Am J Orthod Dentofacial Orthop 2002; 121: 129-35.

Ref ID: 18

59. Memikoglu $\mathbf{T U}$, Iseri $\mathbf{H}$. Effects of a bonded rapid maxillary expansion appliance during orthodontic treatment. Angle Orthod 1999; 69: 251-6.

Ref ID: 22

60. Cross DL, McDonald JP. Effect of rapid maxillary expansion on skeletal, dental, and nasal structures: a postero-anterior cephalometric study. Eur J Orthod 2000; 22: 519-28.

Ref ID: 19

61. Hershey HG, Stewart BL, Warren DW. Changes in nasal airway resistance associated with rapid maxillary expansion. Am J Orthod 1976; 69: 274-84.

Ref ID: 16

62. Moussa R, O'Reilly MT, Close JM. Long-term stability of rapid palatal expander treatment and edgewise mechanotherapy. Am J Orthod Dentofacial Orthop 1995; 108: 478-88.

Ref ID: 72

63. Schwarz GM, Thrash WJ, Byrd DL, Jacobs JD. Tomographic assessment of nasal septal changes following surgical-orthodontic rapid maxillary expansion. Am J Orthod 1985; 87: 39-45.

Ref ID: 13

64. Gray LP. Rapid maxillary expansion and impaired nasal respiration. Ear Nose Throat J 1987; 66: 248-51.

Ref ID: 30

65. Hershey HG, Stewart BL, Warren DW. Changes in nasal airway resistance associated with rapid maxillary expansion. Am J Orthod 1976; 69: 274-84.

Ref ID: 16

66. Gray LP. Results of 310 cases of rapid maxillary expansion selected for medical reasons. J Laryngol Otol 1975; 89: 601-14.

Ref ID: 17 
67. Palmisano RG, Wilcox I, Sullivan CE, Cistulli PA. Treatment of snoring and obstructive sleep apnoea by rapid maxillary expansion. Aust N Z J Med 1996; 26: 428-9.

Ref ID: 27

68. Cistulli PA, Palmisano RG, Poole MD. Treatment of obstructive sleep apnea syndrome by rapid maxillary expansion. Sleep 1998; 21: 831-5.

Ref ID: 24

69. Hartgerink DV, Vig PS, Abbott DW. The effect of rapid maxillary expansion on nasal airway resistance. Am J Orthod Dentofacial Orthop 1987; 92: 381-9. Ref ID: 9

70. Timms DJ. Rapid maxillary expansion in the treatment of nasal obstruction and respiratory disease. Ear Nose Throat J 1987; 66: 242-7.

Ref ID: 31

71. Doruk C, Sokucu O, Sezer H, Canbay EI. Evaluation of nasal airway resistance during rapid maxillary expansion using acoustic rhinometry. Eur J Orthod 2004; 26: 397-401.

Ref ID: 1

72. Hershey HG, Stewart BL, Warren DW. Changes in nasal airway resistance associated with rapid maxillary expansion. Am J Orthod 1976; 69: 274-84.

Ref ID: 16

73. White BC, Woodside DG, Cole P. The effect of rapid maxillary expansion on nasal airway resistance. $J$ Otolaryngol 1989; 18: 137-43.

Ref ID: 2

74. Ngan P, Yiu C, Hu A, Hagg U, Wei SH, Gunel E. Cephalometric and occlusal changes following maxillary expansion and protraction. Eur J Orthod 1998; 20: 237-54.

Ref ID: 71

75. Doruk C, Sokucu O, Sezer H, Canbay EI. Evaluation of nasal airway resistance during rapid maxillary expansion using acoustic rhinometry. Eur J Orthod 2004; 26: 397-401.

Ref ID: 1

76. Cross DL, McDonald JP. Effect of rapid maxillary expansion on skeletal, dental, and nasal structures: a postero-anterior cephalometric study. Eur J Orthod 2000; 22: 519-28.

Ref ID: 19 
This page is intended to be blank. 


\section{APPENDIX A - \\ Institutional Review Board Approval}




\section{APPENDIX B -Area and Volume Measurements}




\section{APPENDIX C -Statistics}




\section{Curriculum Vitae}

Name:

Date of Birth:

Place of Birth:

Education:

August 1988-August 1992

August 1991-June 1995

August 1995-August 1996

August 1996-June 2002

July 2002-April 2005

Professional Membership
Jacqueline Palaisa

October 30, 1970

Uniontown, Pa

\author{
University of Pittsburgh \\ College of Arts and Sciences \\ Combined Dental Major \\ Pittsburgh, Pa \\ Bachelor of Science \\ University of Pittsburgh \\ School of Dental Medicine \\ Pittsburgh, Pa \\ Doctor of Dental Medicine
}

Naval Medical Center San Diego

San Diego, Ca

General Practice Residency,certificate

General Dentistry Practice

United States Navy

WVU School of Dentistry

Dept of Orthodontics

Morgantown, WV

Master of Science

American Association of Orthodontics Omicrom Kappa Upsilon, Beta Chapter American Dental Association

Publication

"Desire to treat HIV-infected patients: similarities and differences across health-care professions” AIDS 1994, Vol 8: 117-121 Co-Author 